\title{
Evaluation of Prevalence of Psychosocial Disorders among University Undergraduate Students in Cross River State, Nigeria
}

\author{
Ntu N. Nkomo \\ Cross River University Of Technology, Nigeria
}

\begin{abstract}
The focus of this paper is on prevalence of psychosocial disorders among university undergraduate students in Cross River State. Psychosocial disorders are otherwise mental or psychological disorders, which affect our mental, social and emotional functioning. They include depressing anxiety, attention disorder, obsessive compulsive disorder, post-traumatic stress disorder, oppositional deficit disorders, bipolar and autism spectrum disorder. The study specifically sought to determine the prevalence of psychosocial disorder and to further ascertain if a significant difference exist between male and female students in the manifestation of psychosocial or mental health disorders. The study population comprised all the university undergraduate students in Cross River State, University of Calabar and Cross River University of Technology, Calabar. A total of 300 students formed the sample. Data collection instrument was a structured questionnaire titled Psychosocial Disorder Questionnaire (PDQ). The major findings were that the prevalence of psychosocial or mental health disorders among university undergraduate students in Cross River State was significantly high. No significant difference was found between male and female students in the manifestations of these disorders. Major recommendations were that student's nutrition be improved to achieve healthy cognitive development, improvement of students housing conditions, bans on sale and use of additive substances in school and reduction of child abuse. It was concluded that the high level of psychosocial or mental health disorder among university undergraduate students is much likely to be responsible for poor performance of students in academics and consequent involvement in various forms of examination malpractice.
\end{abstract}

\section{Introduction}

Art Human development and learning is influenced by myriads of hereditary, environmental, psychological problems. The discussion in this paper shall be centered on psychological and social problems which together form psychosocial challenges. Psychosocial are social and psychological dysfunctions which affect the mental health condition of humans. The behavior of university undergraduate students in Cross River State, in terms of indiscipline, involvement in various forms of social vices and malpractices, total loss of academic focus, lack of aspiration increase anti-social and disruptive behavior on campuses in Nigeria has become so worrisome that it is necessary to find out the prevalence of psychosocial disorders or mental health condition of university undergraduate students in Nigeria.

Some questions that need to be answered are to what extent are these behaviours determined by psychosocial disorders? How do the male and female undergraduate students in Nigeria manifest certain psychosocial disorders?

\section{Literature Review}

Psychosocial disorder is influenced by life experiences involving peer pressure, parental socioeconomic background, cultural practices, religion and interpersonal relationship. Chapresov [1] defined mental health as issues that affect three important components of well-being mentally, emotionally and social component. He furthered that the thinking portion of psychosocial health is known as mental health, which affects one's beliefs and values in life responding positively to situations, accepting mistakes and looking forward for correction. The feeling part of psychosocial health is called emotional health; it includes emotional intelligence which generally points to inability to understand and ménage personal emotions and those of others. The relationship part of mental health is called social health. This aspect of disorder involves the inability to create and maintain healthy relationships with others.

The psychosocial disorder is viewed by Brogaard [2] as a psychological dysfunction in an individual which is associated with distress or impairment and 
reactions which are not culturally expected. Like Chapresov, Brogaard asserts that psychological dysfunction is expressed in the purposeful functioning of cognition, emotions and behavior. In summary therefore, one may safely explain psychosocial disorder as the dysfunction in our thinking or cognitive process emotional and social wellbeing.

Research studies reported by Bantjes, Lochner, Stein and Taljaard [3] conducted by National Institute of Mental health found that one in four adults in the United State is diagnosable for one or more psychological disorder in a given year. Another study conducted in US across 26 universities campuses showed that students experience a wide range of mental health problems. About $45.6 \%$ of university students in their study indicated various symptoms of psychosocial disorders. Another study in South Africa quoted by Bantjes et al., [3]. Showed that about $15 \%$ of university undergraduate students manifested symptoms of psychosocial disorders, 24.5 had suicidal ideation. In a cross-sectional study on mental health status of undergraduate medical trainees in the University of Calabar, Nigeria. Conducted by Oku, Oku, Owaje and Monjok [4] result revealed that $40.2 \%$ of the 451 randomly selected medical students had poor mental health status. Uwadiae and Osasona [5] studied the prevalence of psychosocial distress and tis association with gender among undergraduate students of a Nigerian University and found higher proportions of females $(31.8 \%)$ than males $(28.2 \%)$ indicating symptoms of psychosocial distress. Research by Esan, Esan Folasire and Oluwajulugbe [6] revealed that the prevalence of mental health disorder among medical students in Nigeria is high.

A classification of major categories of psychosocial or mental health disorders describes in the diagnostic and statistical manual or mental disorder (DSM). The latest edition of the diagnostic manual is the DSM-s released in May 2013, quoted by Cherry [7] identified the following as symptoms of psychosocial disorders.

Intellectual disability: Limitation in intellectual function. Autism Spectrum Disorder (ASD): Persistent deficits in social interactions, impairments in occupational functioning and restricted patterns of behavior. Attention-deficit Hyperactivity disorder (ADHD): persistent attention problems, difficulty in settling down, impulsivity and hyperactivity bipolar disorder: regular shifts in moods and energy levels from excitements of sadness, guilt, fatigue. Anxiety disorder: persistent fear, worry, instability. Some types of anxiety include separation anxiety (fear of being watched or judged). Acrophobia (fear of public places) generalized anxiety (worry about everyday events) schizophrenia (lacking ability to distinguish reality and withdrawal) depression: bad mood and lack of interest in pursuing daily life. Obsessive compulsive disorder (OCD): unwanted and repeated thoughts and feelings that drive a repeated action or behavior. Oppositional defiant disorder: this study is considered worthwhile because there seem to be a nexus between the perceived psychosocial disorders and students' academic and social adjustment.

\section{Purpose of the study}

The study sought to find out the prevalence of psychosocial disorders among university undergraduate students in Cross River State.

The specific objectives are:

i. To determine the prevalence of psychosocial disorders among university undergraduate students in Cross River state.

ii. To assess the manifestation of psychosocial disorders between male and female university undergraduate students in Cross River State.

\subsection{Research questions}

i. What is the prevalence of psychosocial disorders among university undergraduate students in Cross River State?

ii. What is the difference in the manifestation of psychosocial disorders between male and female university undergraduate students in Cross River State?

\subsection{Statement of Hypotheses}

i. The level of psychosocial disorders among university undergraduate students in terms of depressing attention disorder, bipolar disorder, generalized anxiety, depressing anxiety and autism spectrums disorder are not significantly high.

ii. Male students do not differ significantly from their female counterparts in their psychosocial on the basis of depressing attention disorder, bipolar disorder, generalized anxiety, depressing anxiety and autism spectrum disorder.

\section{Methodology}

The study adopted the descriptive survey approach since it was aimed at describing the trend of psychosocial disorder that exists among university undergraduate students. The study population comprised university undergraduate students in University of Calabar and Cross River University of Technology. Stratified simple random sampling method was adopted to select a convenient sample. 
Thus 300 undergraduate students comprising males and females were randomly selected from the University of Calabar and Cross River University of Technology as respondents in the research study. Proportionally 180 students comprising $60 \%$ of the respondents were selected from University of Calabar while 120 students comprising $40 \%$ of the respondents were selected from Cross River University of Technology. A total of 194 males and 103 Females responded to the instrument.

Data collection instrument was a fact funding structured questionnaire titled Psychosocial Disorder Questionnaire (PDQ) designed by the author and trial tested against university undergraduate students in University of Uyo, which did not form part of the population of this study. Cronbach alpha reliability coefficient of 0.86 was found, ascertaining the instrument to be reliable.

\section{Results}

The results of the data analysis are presented below:

\subsection{Hypothesis One}

The level of psychosocial disorders among university undergraduate students in terms of depressing attention disorder, bipolar disorder, generalized anxiety, depressing anxiety and autism spectrum disorder are not significantly high. The only variable involved in this hypothesis is psychosocial disorders categorized in terms of depressing attention disorder, bipolar disorder, generalized anxiety, depressing anxiety and autism spectrum disorder. To test this hypothesis, population t-test was employed as presented in Table 1.

Table 1. Result of population t-test of level of psychosocial disorders among University undergraduate students in terms of depressing attention disorder, bipolar disorder, generalized anxiety, depressing anxiety and autism spectrum disorder

\begin{tabular}{|c|c|c|c|c|c|c|c|c|}
\hline $\begin{array}{l}\text { Level } \\
\text { psychological } \\
\text { disorder }\end{array}$ & $\mathbf{N}$ & Mean & $\mu$ & $\begin{array}{l}\text { Std. } \\
\text { Deviation }\end{array}$ & $\begin{array}{l}\text { Std. } \\
\text { Error } \\
\text { mean }\end{array}$ & $\mathbf{t}$ & df & $\begin{array}{l}\text { Sig. (2- } \\
\text { tailed) }\end{array}$ \\
\hline Attention disorder & 297 & 17.8754 & 10.00 & 3.69367 & .21433 & 83.402 & 296 & .003 \\
\hline Bipolar disorder & 297 & 16.5455 & 15.000 & 4.46368 & .25901 & 48.436 & 296 & .010 \\
\hline $\begin{array}{l}\text { Generalized } \\
\text { anxiety }\end{array}$ & 297 & 17.7778 & 12.500 & 3.15443 & .18304 & 97.126 & 296 & .030 \\
\hline Depressing anxiety & 297 & 16.4209 & 15.00 & 4.31700 & .25050 & 65.553 & 296 & .001 \\
\hline $\begin{array}{ll}\begin{array}{l}\text { Autism } \\
\text { disorder }\end{array} & \text { spectrum } \\
\end{array}$ & 297 & 16.4040 & 12.00 & 6.00662 & .34854 & 47.065 & 296 & .000 \\
\hline
\end{tabular}

The result in Table 1 revealed that with the level of psychological disorder, while attention disorder is statistically significant (p-value $.003<.05$ ), bipolar disorder is statistically significant ( $\mathrm{p}$-value $.010<$ .05 ), generalized anxiety is statistically significant ( $\mathrm{p}$ value $.030<.05$ ), depressing anxiety is statistically significant (p-value .001 <.05) and autism spectrum disorder is statistically significant ( $\mathrm{p}$-value $.000<.05$ ). Thus, the level of psychosocial disorders among university undergraduate students in terms of depressing attention disorder, bipolar disorder, generalized anxiety, depressing anxiety and autism spectrum disorder is significantly high.

\subsection{Hypothesis two}

Male students do not differ significantly from their female counterparts in their psychosocial disorder on the basis of depressing anxiety, attention disorder, obsessive compulsive disorder, posttraumatic stress disorder, oppositional deficit disorders, bipolar and autism spectrum disorder. The major independent variable in this hypothesis is gender categorized on the basis of male and female, while the dependent variable is psychological disorder categorized in terms of attention disorder, bipolar disorder, generalized anxiety, depressing anxiety and autism spectrum disorder. To test this hypothesis, independent t-test was employed as presented in Table 2.

The result in Table 2 of gender and psychosocial disorder on the basis of attention disorder, bipolar disorder, generalized anxiety, depressing anxiety and autism spectrum disorder, while attention disorder for male and female is statistically significant ( $p$-value $.002<.05)$, bipolar disorder is statistically significant (p-value .001< .05), generalized anxiety is statistically significant (p-value $.000<.05$ ), depression anxiety is statistically significant (p-value $.009<.05)$, and autism spectrum disorder is statistically significant (p-value $.002<.05$ ).

Thus, the null hypothesis for all the dimension of psychological disorder are significant. This implies that there is a significant gender difference of students on their psychological disorder on the basis of attention disorder, bipolar disorder, generalized anxiety, depressing anxiety and autism spectrum disorder. 
Table 2. Result of gender and psychosocial disorder on the basis of attention disorder, bipolar disorder, generalised anxiety, depressing anxiety and autism spectrum disorder

\begin{tabular}{|c|c|c|c|c|c|c|c|}
\hline $\begin{array}{ll}\begin{array}{l}\text { Gender } \\
\text { disorder) }\end{array} & \text { (attention } \\
\end{array}$ & $\mathrm{N}$ & Mean & $\begin{array}{c}\text { Std. } \\
\text { Deviation } \\
\end{array}$ & Df & $\mathrm{T}$ & p-value & decision \\
\hline Male & 194 & 17.72 & 2.91 & & & & \\
\hline Female & 103 & 16.97 & 2.68 & 295 & 4.43 & .002 & Reject $\mathrm{H}_{\mathrm{o}}$ \\
\hline $\begin{array}{ll}\begin{array}{l}\text { Gender } \\
\text { disorder) }\end{array} & \text { (Bipolar } \\
\end{array}$ & $\mathrm{N}$ & Mean & $\begin{array}{c}\text { Std. } \\
\text { Deviation }\end{array}$ & Df & $\mathrm{T}$ & p-value & Decision \\
\hline $\begin{array}{l}\text { Male } \\
\text { Female }\end{array}$ & 194 & 16.04 & 3.77 & 295 & 3.17 & .001 & Reject $\mathrm{H}_{\mathrm{o}}$ \\
\hline $\begin{array}{l}\text { Gender (generlised } \\
\text { anxiety) }\end{array}$ & $\mathrm{N}$ & Mean & $\begin{array}{c}\text { Std. } \\
\text { Deviation }\end{array}$ & Df & $\mathrm{T}$ & p-value & Decision \\
\hline $\begin{array}{l}\text { Male } \\
\text { Female }\end{array}$ & $\begin{array}{l}194 \\
103 \\
\end{array}$ & $\begin{array}{l}16.51 \\
17.17\end{array}$ & $\begin{array}{l}3.02 \\
2.15 \\
\end{array}$ & 295 & 4.18 & .000 & Reject $\mathrm{H}_{\mathrm{o}}$ \\
\hline $\begin{array}{l}\text { Gender (depressing } \\
\text { anxiety) }\end{array}$ & $\mathrm{N}$ & Mean & $\begin{array}{c}\text { Std. } \\
\text { Deviation }\end{array}$ & Df & $\mathrm{T}$ & p-value & decision \\
\hline $\begin{array}{l}\text { Male } \\
\text { Female }\end{array}$ & 194 & $\begin{array}{l}17.12 \\
17.31\end{array}$ & $\begin{array}{l}2.84 \\
2.60\end{array}$ & 295 & 4.63 & .009 & Reject $\mathrm{H}_{\mathrm{o}}$ \\
\hline $\begin{array}{l}\text { Gender } \quad \begin{array}{l}\text { (autism } \\
\text { spectrum disorder) }\end{array} \\
\end{array}$ & $\mathrm{N}$ & Mean & $\begin{array}{c}\text { Std. } \\
\text { Deviation } \\
\end{array}$ & Df & $\mathrm{T}$ & p-value & decision \\
\hline $\begin{array}{l}\text { Male } \\
\text { Female }\end{array}$ & $\begin{array}{r}194 \\
103 \\
\end{array}$ & $\begin{array}{l}17.71 \\
17.02 \\
\end{array}$ & $\begin{array}{l}2.01 \\
2.60 \\
\end{array}$ & 295 & 4.63 & .004 & Reject $\mathrm{H}_{\mathrm{o}}$ \\
\hline
\end{tabular}

\section{Summary of Finding}

Results from the data obtained revealed that:

1) The level of psychosocial disorders among university undergraduate students in Cross River State is significantly high.

2) Male students do not differ significantly from their female counterparts in their psychosocial disorder.

The first finding that the level of psychosocial disorder is significantly high among university undergraduate students in Cross River State corroborates findings reported by Bantjes, Lochner, Stein and Taljarrd [3] in a study conducted by National Institute of Mental Health in the US. The finding of the present study is also in consonance with the findings of Oku, Oku, Owaje and Monjok [4] who found that medical trainees in the university of Calabar, Cross River State, Nigeria had poor mental health status. The significantly high level of

psychosocial disorder among university undergraduate students in Cross River State is worrisome. The researcher predicts this might have a negative influence on the academic performance of undergraduate students. Since Chapresov [1] obs- erved that mental health or psychological disorder affects three components of well-being mental, social and emotional. He concluded that the thinking aspect of psychological disorder called mental health negatively affects one's level of positive response to situations, accepting mistakes and taking corrections. The major outcry in Nigerian Universities today is the poor performance of students in academics and the consequent involvement in various forms of examination malpractice by university undergraduate students in Nigeria. This can be linked to the high levels of psychosocial disorders found among undergraduate students.

The finding that male and female students do not differ significantly in the levels of psychosocial disorder contradicts the finding of Uwadiae and Osasona [5] who found higher proportions of females than males indicating symptoms of psychosocial distress among university undergraduate students in Nigeria.

\section{Conclusion}

Psychosocial disorders or mental health issues are prevalent among university undergraduate students in Cross River State, Nigeria. This condition is very much likely connected with the poor performance in academics by undergraduate students and the high- 
level involvement in various forms of examination malpractice.

\section{Recommendations}

The following are some measures of reducing mental health issues

1. Improve the nutrition of students which leads to a healthy cognitive development and proper coordination.

2. Provide adequate accommodation for students as the health effect of housing improvement suggests a promising impact on physical and mental health outcomes.

3. Placing strict restrictions on the use of addictive substances by students through banning the sales of addictive substances in the university environment.

4. Reducing child abuse and neglect can successfully reduce of risk of psychosocial disorder.

5. Encourage extra-curricular programmes in school. This can influence positive mental health and reduce risk factors and emotional and behavioural problems through social - emotional learning.

\section{References}

[1] Chapresov, A. (2018)., Psychosocial health. Retrieved from https://study.com. (Access Date: 3 February 2019).

[2] Brogaard, B., (2015). Psychological disorder. Retrieved from www.psychologytoday.com. On 1st November 2018.

[3] Bantjes, J., Lochmer, C., Stein, D. J. and Taljaard, L., (2017). Mental health issues facinguniversity students. Retrieved from www.news.uct.ac.za. On 28th October 2018.

[4] Oku, A., Oku, O., Owaaje, E. and Monjok, E., (2015). An assessment of mental health status of undergraduate medical trainees in the University of Calabar, Nigeria. A Cross Sectional Study Journal of Medical sciences 3(2), 356-362.

[5] Uwadiae, E. and Osasona, S. O., (2016). Psychological distress amongst undergraduate students of a Nigerian university. Central African Journal of Medicine 62, 5-8.

[6] Esan, O., Esan, A., Folasire, A., and Oluwajulugbe (2019). Mental health and wellbeing of medical students in Nigeria: A systematic review. Internal Review of Psychiatry, 13(7), 661-672.

[7] Cherry, K., Steven-Gans, M. D., (2018). Psychological disorders. Retrieved from www.verywellmind.com. On 30th January 2019. 